\title{
The role of calcifying nanoparticles in biology and medicine
}

\author{
This article was published in the following Dove Press journal: \\ International Journal of Nanomedicine \\ 18 January 2012 \\ Number of times this article has been viewed
}

\author{
Anton G Kutikhin \\ Elena B Brusina \\ Arseniy E Yuzhalin \\ Department of Epidemiology, \\ Kemerovo State Medical Academy, \\ Kemerovo, Russian Federation
}

Correspondence: Anton G Kutikhin Darvina Street 2-9, Kemerovo,

Russian Federation, 650025

Tel +7 3842751744

Mob +7905 9122699

Fax +7 3842751744

Email antonkutikhin@gmail.com

\begin{abstract}
Calcifying nanoparticles (CNPs) (nanobacteria, nanobacteria-like particles, nanobes) were discovered over 25 years ago; nevertheless, their nature is still obscure. To date, nobody has been successful in credibly determining whether they are the smallest self-replicating life form on Earth, or whether they represent mineralo-protein complexes without any relation to living organisms. Proponents of both theories have a number of arguments in favor of the validity of their hypotheses. However, after epistemological analysis carried out in this review, all arguments used by proponents of the theory about the physicochemical model of CNP formation may be refuted on the basis of the performed investigations, and therefore published data suggest a biological nature of CNPs. The only obstacle to establish CNPs as living organisms is the absence of a fairly accurately sequenced genome at the present time. Moreover, it is clear that CNPs play an important role in etiopathogenesis of many diseases, and this association is independent from their nature. Consequently, emergence of CNPs in an organism is a pathological, not a physiological, process. The classification and new directions of further investigations devoted to the role of CNPs in biology and medicine are proposed.
\end{abstract}

Keywords: nanobacteria, nanobacteria-like particles, diseases, infectious agents, hydroxyapatite

\section{Introduction}

Calcifying nanoparticles (CNPs) (nanobacteria, nanobacteria-like particles, nanobes) were discovered as cell culture contaminants by Kajander et al more than 25 years ago, and the first results of their work were published some years later. ${ }^{1}$ However, the question of their nature is actively discussed even at the present time. Despite recent investigations, as described in Table 1, there has not been a comprehensive study to credibly determine whether CNPs are the smallest self-replicating form of life on Earth, or whether they represent mineralo-protein complexes without any relation to bacteria. Proponents of both theories have a number of arguments, often mutually exclusive, in favor of the validity of their own hypotheses (Table 2), and at the present time the theory about CNPs being mineralo-protein complexes has the better hand. ${ }^{2-12}$ It is a challenge to collect all the existing information about the nature and basic properties of CNPs and to analyze it to compare the power of the arguments from both sides. Moreover, it seems to be useful to consider the role of CNPs in etiopathogenesis of various diseases, since several articles devoted to this problem have been published (see below). It can be crucially significant for medicine since CNPs can be absolutely new causative agents of many diseases and may 
Table I Properties of CNPs

Properties of calcifying nanoparticles

Morphological properties $\quad 80-500 \mathrm{~nm}$ in diameter (can pass through $100 \mathrm{~nm}$ filters). ${ }^{1}, 16$

Usually have coccoid, coccobacillar, or bacillar form, mineralized "igloo-like" structures. ${ }^{1,16}$

Have hydroxyapatite shell, cellular-membranous structure, and central cavity. ${ }^{1,16}$

Can form microscopic colonies ( $>$ I mm in diameter) under low nutrient concentrations in the

environment. ${ }^{1.16}$

Divide by binary fission, fragmentation, and gemmation. ${ }^{1,16}$

Can form thermoresistant biofilms $\mathbf{s}^{1,16}$

Tinctorial properties Gram-negative; can be stained by DNA-specific dyes ${ }^{16-24}$ (Hoechst 33258 at a concentration of $5 \mu g / \mathrm{mL}$ for 50 minutes, propidium iodide, PicoGreen - they are specific after the filtration through $0.10-0.22 \mu \mathrm{m}$ pores, staining after demineralization is optimal); can be revealed by von Kossa staining; ${ }^{16}$ staining by $2 \%$ uranyl acetate (possibly with lead citrate) can detect specific mucus on the hydroxyapatite shell;' in the mineralized state can be stained by alizarin red $\mathrm{S} ;{ }^{26}$ can be stained by phosphotungstic acid ${ }^{16}$

Resistance and sensitivity

Resistant to $90^{\circ} \mathrm{C}$ heating for I hour.'

Resistant to $\gamma$-irradiation up to 30 kGray. ${ }^{1,16}$

Resistant to $5 \% \mathrm{NaCl}$ solution.'

In the mineralized state are resistant to lysozyme, proteinase K, certain other proteinases, lipases, amylases, alkali, ultrasound, X-ray, detergents, and solvents.'

Temperatures under $37^{\circ} \mathrm{C}$ suppress replication and prevent biofilm formation.'

Resistant to a wide spectrum of antimicrobial therapeutics: ${ }^{30}$ aminoglycosides (in pharmacological concentrations), chloramphenicol, lincosamides, cephalosporins, macrolides, fluoroquinolones,

glycopeptides (in pharmacological concentrations), polymyxins, antituberculous agents, aminocyclitol, spectinomycin.

Sensitive to tetracyclines, ${ }^{30}$ ampicillin, ${ }^{30}$ trimethoprim, ${ }^{30}$ trimethoprim-sulfamethoxazole,${ }^{30}$ nitrofurantoin, ${ }^{30}$ 5 -fluorouracil, ${ }^{30}$ cytosine arabinoside, ${ }^{30}$ antimycin $A,{ }^{22}$ sodium azide, ${ }^{22}$ potassium cyanide, ${ }^{22}$ bisphosphonates (etidronate, clodronate), ${ }^{30} 6$-aminocaproic acid; ${ }^{30}$ in-vitro growth can be inhibited by EDTA, EGTA, and citrate $^{22}$

Culture properties

Doubling time is 3 days; in media without serum, 6 days. ${ }^{1,16}$

Passage can be performed in DMEM or RPMI- 1640 independently of the presence of serum. ${ }^{1,16}$

Optimal atmosphere for growth should contain $5 \% \mathrm{CO}_{2}$ and $95 \%$ air. ${ }^{1,16}$

Sensitive to $\beta$-mercaptoethanol, which stimulates growth of anaerobes, but cannot be cultivated under strictly anaerobic conditions. ${ }^{22}$

Calcify when serum concentration in the culture media is lower than $5 \%$.'

Cytotoxic for fibroblasts and lymphocytes ${ }^{16}$

Biochemical properties

Metabolism is 10,000 times slower than in Escherichia coli.'

Incorporate uridine (into the expected nucleic acid), ${ }^{16,21}$ methionine ${ }^{16}$ and aspartic acid ${ }^{25}$ (into the expected system of protein biosynthesis).

Calcify under physiological pH (7.4). ${ }^{1,16}$

Urease negative ${ }^{16}$

Detection methods

Bacterioscopic (DNA-specific dyes Hoechst 33258, propidium iodide, PicoGreen, staining after a demineralization is optimal) using scanning and transmission electron microscopy, ${ }^{16-24}$ von Kossa staining, which is specific to calcium compounds, ${ }^{16}$ staining by $2 \%$ uranyl acetate (possibly with lead citrate) to detect specific mucus on the hydroxyapatite shell,' staining by alizarin red $\mathrm{S}$ in the mineralized state, ${ }^{26}$ staining by phosphotungstic acid, ${ }^{16}$ after the long-term cultivation light microscopy with von Kossa staining is possible to be used for detection. ${ }^{1.16}$

Bacteriological (cultivation in DMEM or RPMI- 1640 without serum under $37^{\circ} \mathrm{C}$ for $4-6$ weeks after filtration through $0.10-0.22 \mu \mathrm{m}$ pores), ${ }^{1,16}$ replication can be assessed by spectrophotometry $(650 \mathrm{~nm}$ wavelength). ${ }^{16}$

Serological (CNP antigens and anti-CNP monoclonal antibodies 8/0 [to porin], ${ }^{17,20} 5 / 2$ [to peptidoglycan], ${ }^{17,20}$ and 8DI0 [to porin] ${ }^{21,32,43}$ of NanoBiotech Pharma, Tampa, FL) - ELISA, ${ }^{43}$ immunohistochemistry, ${ }^{32}$

immunofluorescence reaction, ${ }^{32}$ immunoblotting, Ouchterlony immunodiffusion. ${ }^{20}$

Genomic (PCR), but there is doubt that existing primers are obtained on the basis of CNP nucleic acids, and not on the basis of nucleic acids of contaminating bacteria. ${ }^{2}$

Proteomic (sodium dodecyl sulfate polyacrylamide gel electrophoresis with further identification of protein bands by mass spectrometry ${ }^{22}$

Methods of treatment comET-therapy (tetracycline, EDTA, and mixture of nutrients) 36,41

of CNP-associated diseases

Abbreviations: CNP, calcifying nanoparticles; DMEM, Dulbecco's modified Eagle's medium; EDTA, ethylenediaminetetraacetic acid; EGTA, ethyleneglycoltetraacetic acid; ELISA, enzyme-linked immunosorbent assay; PCR, polymerase chain reaction; RPMI-1640, Roswell Park Memorial Institute 1640 medium. 
Table 2 Arguments supporting and contradicting the hypothesis that CNPs are nanobacteria, a unique form of life on Earth

\section{Arguments in favor of theory that CNPs are living organisms (nanobacteria)}

Morphological similarity to bacteria, cultivation on various media, binary fission ${ }^{16}$ Staining by DNA-specific dyes

(Hoehst 33258, propidium iodide, PicoGreen) ${ }^{16-24}$

Presence of DNA and RNA in ratio characteristic for Escherichia coli ${ }^{19,22}$ Identification of DNA and RNA by electron microscopy ${ }^{49}$ Incorporation of $\left[{ }^{35} \mathrm{~S}\right]$ methionine, ${ }^{16}\left[{ }^{3} \mathrm{H}\right] \mathrm{L}$-aspartic acid, ${ }^{25}$ and $\left[5-{ }^{3} \mathrm{H}\right]$ uridine during cultivation ${ }^{16,21}$
Arguments in favor of theory that CNPs are a physicochemical phenomenon (mineralo-protein complexes)

Extremely small size (often smaller than $140 \mathrm{~nm}$ - presumably minimum possible size limit of life forms)

Absence of fairly accurately sequenced genome
The presence of endotoxin and cross-reactivity with lipopolysaccharide of Chlamydia spp. and with antigens of Bartonella spp ${ }^{18}$

Susceptibility to a number of antimicrobial chemotherapeutics possessing antimetabolic activity and not possessing the chelating activity, ${ }^{30}$ (nitrofurantoin, trimethoprim, trimethoprim-sulfamethoxasole), to 5-fluorouracil, cytosine arabinoside, 6-aminocaproic acid, ${ }^{30}$

antimycin $A$, sodium azide, potassium cyanide ${ }^{22}$

Acceleration of replication and reduction of formation of biofilms after photobiostimulation ${ }^{29}$

Presence of proteins, including bacterial ones, after a demineralization ${ }^{16,20,21}$ (EF-Tu, ${ }^{22,26}$ EF-G, ${ }^{26}$ GroEL, ${ }^{22}$

dihydrolipoamide acetyltransferase of pyruvate dehydrogenase, ${ }^{22}$

polyribonucleotide nucleotidyl transferase, ${ }^{22}$ fructose

binding aldolase, ${ }^{26}$ chaperone $\mathrm{ClpB}^{26}$ )

Stimulation of replication by $\beta$-mercaptoethanol and absence

of replication under strictly anaerobic conditions ${ }^{22}$

Pathogenic activity of demineralized $\mathrm{CNPs}^{31}$ and distinct pathogenicity of CNPs and hydroxyapatite crystals ${ }^{23}$
Association of hydroxyapatite of CNPs with albumin, ${ }^{6,8-10}$ fetuin-A, 5,9,10 apolipoproteins, ${ }^{9,10}$ proteins of coagulation and anticoagulation systems, ${ }^{9,10}$ immunoglobulins, ${ }^{9,10}$ macroglobulins, ${ }^{9,10}$ complement proteins, ${ }^{9,10}$ precursors of interleukins, ${ }^{10}$ kininogen,, 10 fibronectin, ${ }^{9,10}$ vitronectin, ${ }^{9,10}$ vitamin D-binding protein, $, 9,10$ precursor of antitrypsin, ${ }^{9,10}$ serotransferrin, ${ }^{10}$ syntrophin,, 10 Tamm-Horsfall glycoprotein, ${ }^{10}$ glycogenin, ${ }^{10}$ serum component of amyloid, ${ }^{10}$ salivary amylase, ${ }^{10}$ cytoskeleton proteins, ${ }^{9}$ adenosylhomocysteinase, ${ }^{9}$ hemoglobin subunits ${ }^{9}$ and other proteins Cross-reactivity of MoAbs to presumably specific CNP proteins with serum proteins - albumin ${ }^{6,8-10}$ and fetuin- $A^{5,9,10}$

Morphological similarity to various mineral and mineralo-protein complexes containing inorganic calcium, phosphorus, and apatite compounds, and also proteins and phospholipids $2,6,8-10$

Resistance to DNase and RNase activity ${ }^{5}$

Critical influence of inert gas, $\mathrm{CO}_{2}$, and $\mathrm{NaHCO}_{3}$ concentration on CNP replication ${ }^{6}$

CNP formation under physiological serum conditions after certain physiological alterations of homeostasis, which is not characteristic of living organisms ${ }^{5-10}$

Abbreviations: CNP, calcifying nanoparticle; MoAb, monoclonal antibody; EF-Tu, elongation factor thermo unstable; EF-G, elongation factor G.

determine their course, affecting rapidity, severity, therapeutic resistance and sensitiveness, and prognosis of mentioned disorders. The main aims of this review were to perform an analysis of the role of CNPs in biology and medicine from a fundamental and clinical point of view, to describe and to analyze the situation in the field, and to determine new directions for further investigations. To the best of the authors' knowledge, this review comprises all published articles on the abovementioned topic.

\section{CNPs - physicochemical phenomenon or bacteria?}

A more thorough analysis of existing arguments may reveal the following:
- According to the research of Maniloff, ${ }^{13}$ the smallest possible size of a self-replicating life form is approximately $140 \mathrm{~nm}$, but results of an investigation performed by Glass et $\mathrm{al}^{14}$ have shown that Mycoplasma laboratorium may reach even smaller sizes, having only 387 proteincoding genes and 43 RNA-coding genes, which is enough for independent existence. Moreover, according to the calculations of Volke, ${ }^{15}$ if water in a cell is reduced from $70 \%$ (as in Mycoplasma spp.) to $20 \%$, the size of the bacterial cell may shrink to $75 \mathrm{~nm}$ whilst its viability would still be maintained. Therefore, CNPs being life forms cannot be ruled out based on their extremely small size alone. Also, it is not possible to rule out the uniqueness of the replicative and metabolic mechanisms 
of CNPs requiring a smaller size for proper functioning, and these mechanisms can feasibly be characterized by a greater compactness compared with their analogs in other organisms.

- Although the genome of CNPs is still not credibly deciphered (although in certain studies the sequencing was conducted, it is possible to suspect a contamination of analyzed samples by another bacteria, eg, Phyllobacterium myrsinacearum $^{2}$ ), a number of investigations have shown positive DNA-specific staining of CNPs. ${ }^{16-24}$ Furthermore, Hudelist et $\mathrm{al}^{19}$ and Kumar et $\mathrm{al}^{22}$ were successful in extracting DNA and RNA from CNPs, indicating the presence of nucleic acids. The suggestion that nucleic acids are only bound to highly charged molecules of mineralo-protein complexes outside and are not synthesized in $\mathrm{CNPs}^{12}$ can be disproved by the results of Ciftçioglu et al, ${ }^{17}$ Khullar et al, ${ }^{20}$ Miller et al, ${ }^{21}$ and Kumar et al, ${ }^{22}$ who observed DNA-specific staining of already demineralized CNPs, which could not have been possible in the case of a simple binding of nucleic acids outside by a mineralo-protein shell. In addition, Kajander and Ciftçioglu ${ }^{16}$ and Miller et $\mathrm{al}^{21}$ have shown incorporation of $\left[5-{ }^{3} \mathrm{H}\right]$ uridine by CNPs during cultivation, suggesting that CNPs have metabolism and produce their own nucleic acids. Indirect testimony of this fact is that Kajander and Ciftçioglu ${ }^{16}$ and Puskas et $\mathrm{al}^{25}$ revealed incorporation of $\left[{ }^{35} \mathrm{~S}\right]$ methionine and $\left[{ }^{3} \mathrm{H}\right] \mathrm{L}$-aspartic acid, respectively, by CNPs during incubation, proving the presence of their own system of protein biosynthesis, which is impossible without nucleic acids. One more argument in favor of the validity of such a statement is an identification among proteins that are characteristic for CNPs, elongation translation factors (elongation factor thermo unstable [EF-Tu $]^{22,26}$ and elongation factor $G$ $\left.[\mathrm{EF}-\mathrm{G}]^{26}\right)$, polyribonucleotide nucleotidyl transferase, ${ }^{22}$ and chaperones GroEL ${ }^{22}$ and $\mathrm{C} 1 \mathrm{pB},{ }^{26}$ which are similar to their prokaryote analogs. Published data suggest with high probability that CNPs have intrinsic nucleic acids (and, consequently, their own replication system) and an intrinsic protein biosynthesis system.

- Although proteomic analysis carried out in certain studies $^{5,8-10}$ revealed a number of serum proteins in the composition of CNPs and did not find specific bacterial proteins, allowing the conclusion that these complexes have a mineralo-protein nature, data obtained by Kajander and Ciftçioglu, ${ }^{16}$ Khullar et al, ${ }^{20}$ Miller et al, ${ }^{21}$ Kumar et al, ${ }^{22}$ and Shiekh et $\mathrm{al}^{26}$ counter this suggestion since in indicated investigations bacterial proteins were identified in the structure of CNPs. The suggestion of there being an occasional association of these proteins with the mineralo-protein shell of CNPs is contradicted by studies by Khullar et al, ${ }^{20}$ Miller et al, ${ }^{21}$ Kumar et al, ${ }^{22}$ and Shiekh et al, ${ }^{26}$ since in these studies, protein composition of already demineralized CNPs was analyzed. It is important to note that all proteins detected in the investigations of Kumar et $\mathrm{al}^{22}$ and Shiekh et $\mathrm{al}^{26}$ are bacterial and are related only to the replication system (polyribonucleotide nucleotidyl transferase ${ }^{22}$ ), the protein biosynthesis system (EF-Tu, ${ }^{22,26} \mathrm{EF}-\mathrm{G},{ }^{26}$ chaperones GroEL ${ }^{22}$ and $\mathrm{C} 1 \mathrm{pB}^{26}$ ), or the metabolic system (dihydrolipoamide acetyltransferase of pyruvate dehydrogenase $\mathrm{e}^{22}$ and fructose binding aldolase ${ }^{26}$ ), which is consistent with the hypothesis that CNPs have only a limited number of intrinsic proteins, and all of them belong only to vitally important systems. Moreover, incorporation of $\left[{ }^{35} \mathrm{~S}\right]$ methionine ${ }^{16}$ and $\left[{ }^{3} \mathrm{H}\right] \mathrm{L}$-aspartic acid $^{25}$ by CNPs during cultivation, as discussed above, points to the presence in CNPs of their own system of protein biosynthesis. As a consequence, proteomic analysis also verifies the theory of CNPs being the smallest self-replicating life forms on Earth.

- Cross-reactivity of monoclonal antibodies (MoAbs) to putative specific proteins of CNPs (porin and peptidoglycan) with serum proteins (albumin ${ }^{6,8-10}$ and fetuin- $\mathrm{A}^{5,9,10}$ ) revealed in a number of studies, according to the opinion of their authors, has shown a falsity of the conclusions obtained in former investigations in which these MoAbs were used. However, it can explain only negative results obtained in studies devoted to the relation between the level of CNP antigens and anti-CNP antibodies and the features of various diseases, whilst in almost all papers (Table 3 ), on the contrary, positive results were obtained. A permanent cross-reaction is not possible, since albumin and fetuin-A can always be detected in serum under normal conditions, and thus CNP antigens should be revealed in the serum of nearly all subjects. In reality, however, this was not found to be the case (only 5\% of positive subjects in the Finnish population ${ }^{27}$ ). Applied MoAbs thereby have sufficient levels of specificity, and consequently, their cross-reactions with albumin and fetuin-A cannot prove an absence of suggested bacterial proteins (porin and peptidoglycan) in their composition, as was proposed in articles by $\mathrm{Wu}$ et $\mathrm{al},{ }^{8}$ Young et al, ${ }^{9,10}$ Raoult et al, ${ }^{5}$ and Martel and Young. ${ }^{6}$

- Morphological similarity of CNPs to various mineral and mineralo-protein complexes ${ }^{2,6}$ cannot be an argument 
for their physico-chemical nature since they are equally similar to bacteria. ${ }^{16}$ Besides, morphology itself cannot explain the nature of CNPs and should not be used by proponents of both theories as objective testimony.

- Raoult et $\mathrm{al}^{5}$ proposed that CNPs do not contain nucleic acids since in their investigation they were resistant to DNAse and RNAse, continually replicating independently of the presence of these enzymes in culture medium. Nevertheless, it can be explained by the protective role of the mineral shell of CNPs since preliminary demineralization was not carried out. Furthermore, after demineralization, replication of CNPs ceases or decreases sharply, ${ }^{26}$ which makes assessment of the influence of DNAse and RNAse upon it very difficult. Therefore, resistance of CNPs to the action of nucleases found in this research cannot be an argument in favor of their physicochemical nature.

- Martel and Young ${ }^{6}$ revealed that characteristics of CNP replication directly depend on the atmosphere of cultivation (in an atmosphere containing 100\% inert gas, replication is higher than in one containing $5 \% \mathrm{CO}_{2}$ or $100 \% \mathrm{CO}_{2}$ ) and on $\mathrm{NaHCO}_{3}$ concentration in culture medium (when it is high, replication accelerates; when it is low, it slows). These results enabled the authors of that study to propose a chemical model of CNP formation on the basis of certain reaction equations, which according to their opinion, completely subverted the theory of their biological nature. ${ }^{6}$ However, this model explains only the formation of the CNP mineral shell and is not related to the presence or absence of nucleic acids in their structure. Also, published data indicate the impossibility or almost complete cessation of CNP replication without a mineral shell, ${ }^{26}$ which proves the necessity of the presence of nucleic acids and proteins as a mineral shell for successful replication. The model suggested by Martel and Young ${ }^{6}$ does not contradict but affirms this hypothesis: when conditions for a mineral shell (the lion's share of which consists of calcium compounds, particularly of calcium phosphate and carbonate) formation are not appropriate, CNP replication ceases or sharply decreases; whilst under conditions promoting its formation, CNP replication is enhanced. This chemical model logically corresponds with the theory of CNPs being the smallest self-replicating life forms.

- In a number of studies, ${ }^{5-10}$ it has been proposed that CNPs may be formed under physiological conditions of serum (even of $\gamma$-irradiated serum ${ }^{7}$ ) as mineralo-protein complexes during certain alterations in homeostasis within normal limits, and consequently, they cannot be live objects. Nevertheless, Mathew et $\mathrm{al}^{28}$ indicated that CNPs may successfully replicate even in the absence of serum, which points to independence of their replication from serum proteins. It is important to note that inorganic hydroxyapatite crystals did not replicate independently of the presence of serum in culture medium in this research, and CNPs were not observed in control serum-containing media under the same culture conditions. ${ }^{28}$ Moreover, in epidemiological studies devoted to the association of CNPs with risk of various diseases (Table 3), CNP antigens and anti-CNP antibodies were detected significantly more often in cases compared with controls. (See the discussion about the specificity of CNP antigens and of MoAbs to bacterial proteins of CNPs above.) Furthermore, Khullar et al, ${ }^{20}$ Miller et al, ${ }^{21}$ Kumar et al, ${ }^{22}$ and Shiekh et $\mathrm{al}^{26}$ found bacterial proteins that are absent in serum under physiological conditions in the composition of demineralized CNPs. All these data, evidently, contradict the hypothesis of CNPs being physicochemical complexes formed from ubiquitous minerals and proteins of serum and other biological liquids under homeostasis conditions, countering the theory proposed by Raoult et $\mathrm{al},{ }^{5}$ Martel et al, ${ }^{6,7} \mathrm{Wu}$ et al, ${ }^{8}$ and Young et al. ${ }^{9,10}$ Obviously, emergence of CNPs in the organism is a pathological, not physiological, process.

Thereby, all arguments used by proponents of the theory of CNPs being mineralo-protein complexes (ie, the physicochemical model of CNP formation) may be refuted on the basis of investigations carried out. Moreover, the fact that Hjelle et $\mathrm{al}^{18}$ revealed cross-reactivity of MoAbs to CNP bacterial proteins (porin and peptidoglycan) with lipopolysaccharide of Chlamydia spp. and with antigens of Bartonella spp., which points to the presence of similar bacterial proteins in the CNP structure, testifies against this hypothesis as well. A stochastic association of these proteins with mineralo-protein complexes is excluded, since it is absolutely impossible that they could be bound to CNPs in the majority of examined samples. Furthermore, replicative activity of CNPs increases during photobiostimulation ${ }^{29}$ and during exposure to $\beta$-mercaptoethanol, ${ }^{22}$ indicating their biological nature (characteristics of replication of mineralo-protein complexes during such influence are not elevated). Without oxygen, CNPs do not replicate. ${ }^{22}$ Taking into account that $\beta$-mercaptoethanol stimulates the growth of aerobes, ${ }^{22}$ it is possible to suggest that CNPs are facultative anaerobes or microaerophilic microorganisms. Susceptibility of CNPs to a number of chemotherapeutics possessing 
antimetabolic activity, suppressing biosynthesis of nucleic acids and proteins as well as respiratory enzyme functioning (nitrofurantoin, trimethoprim, trimethoprim-sulfamethoxasole, 5-fluorouracil, cytosine arabinoside, 6-aminocaproic acid, antimycin A, sodium azide, potassium cyanide) and not possessing the chelating activity, ${ }^{30}$ can also be testimony of the presence of their own system of replication, protein biosynthesis, and metabolism, which points to their biological nature. Finally, CNPs may cause pathological processes in blood vessels even without a mineral shell; ${ }^{31}$ this may indicate the presence of specific immunogenic bacterial protein antigens in their structure, and also, these proteins may have toxin-like activity. The ability of hydroxyapatite crystals to cause the formation of black pigment gallstones after an injection into rabbit gallbladder was several times lower than with the injection of CNPs, ${ }^{23}$ which points to additional CNP pathogenic mechanisms and contradicts the hypothesis of an inorganic nature and indicates a biological origin.
Published data suggest a biological nature of CNPs, making valid the term "nanobacteria," originally proposed by Kajander et al. ${ }^{1}$ The only obstacle in establishing CNPs as living organisms is an absence of a fairly accurately sequenced genome at the present time, but it itself is not able to counter the theory that they are the smallest selfreplicating life forms on Earth in favor of the theory that they are physicochemical mineralo-protein complexes.

\section{The role of CNPs in etiopathogenesis of diseases}

Many studies in the literature show the significant role of CNPs in the etiopathogenesis of various diseases, particularly of disorders related to pathological calcification (Table 3). Martel et $\mathrm{al}^{7}$ hypothesized that it is incorrect to apply widely used $\gamma$-irradiated serum as a component of culture medium for CNPs since the $\gamma$-irradiation that is used for serum sterilization does not in fact have a sterilizing effect. However, all

Table 3 The relation of CNPs to various diseases

\begin{tabular}{|c|c|c|}
\hline Study & Disease or pathological condition & $\begin{array}{l}\text { Method of detection of association between CNPs } \\
\text { and disease or pathological condition }\end{array}$ \\
\hline Kajander and Ciftçioglu' ${ }^{16}$ & Nephrolithiasis & Serological, bacterioscopic, bacteriological \\
\hline Ciftcioglu et al ${ }^{17}$ & Nephrolithiasis & Serological, bacterioscopic, bacteriological \\
\hline Hjelle et $\mathrm{al}^{18}$ & Polycystic kidney disease & Serological, bacterioscopic, bacteriological \\
\hline Sedivy and Battistutti ${ }^{46}$ & $\begin{array}{l}\text { Formation of psammoma bodies in ovarian malignant } \\
\text { tumors }\end{array}$ & Serological \\
\hline Hudelist et al ${ }^{19}$ & $\begin{array}{l}\text { Formation of psammoma bodies in ovarian malignant } \\
\text { tumors }\end{array}$ & Serological \\
\hline Khullar et $\mathrm{al}^{20}$ & Nephrolithiasis & Serological, bacterioscopic, bacteriological \\
\hline Maniscalco et $\mathrm{al}^{41}$ & Coronary artery calcification & Serological \\
\hline Miller et $\mathrm{al}^{21}$ & Calcification of coronary arteries and cardiac valves & Serological, bacterioscopic, bacteriological \\
\hline Pretorius et $\mathrm{al}^{48}$ & HIV infection & Serological \\
\hline Puskás et al ${ }^{25}$ & Atherosclerotic plaques & Serological, bacterioscopic, bacteriological \\
\hline Shoskes et $\mathrm{al}^{36}$ & Type III chronic prostatitis/chronic pelvic pain syndrome & Serological \\
\hline Wen et $\mathrm{al}^{47}$ & Cholecystolithiasis & Serological, bacterioscopic, bacteriological \\
\hline Kumar et $\mathrm{al}^{22}$ & Randall's plaques & Serological, bacterioscopic, bacteriological \\
\hline Shiekh et $\mathrm{al}^{26}$ & Renal tubular calcification & Bacteriological (animal model) \\
\hline Wang et $\mathrm{al}^{23}$ & Black pigment gallstones & Serological, bacterioscopic, bacteriological (animal model) \\
\hline Agababov et $\mathrm{al}^{49}$ & Pathological placental calcification & Bacterioscopic \\
\hline Bratoz-Perez et al $^{42}$ & Aortic valves calcification & Bacterioscopic, bacteriological \\
\hline Ciftcioglu et $\mathrm{al}^{32}$ & Randall's plaques & Serological, bacterioscopic, bacteriological \\
\hline Schwartz et $\mathrm{al}^{31}$ & Calcification of arteries with damaged endothelium & Bacterioscopic, bacteriological (animal model) \\
\hline Zhou et $\mathrm{al}^{37}$ & Type III prostatitis & Serological, bacterioscopic, bacteriological \\
\hline Candemir et $\mathrm{al}^{43}$ & Mitral annular calcification & Serological \\
\hline Chen et $\mathrm{al}^{33}$ & Nephrolithiasis & Serological, bacterioscopic, bacteriological \\
\hline Hu et $\mathrm{al}^{44}$ & $\begin{array}{l}\text { Calcification of cardiac valves during rheumatic } \\
\text { heart disease }\end{array}$ & Serological, bacterioscopic, bacteriological \\
\hline Hu et $\mathrm{al}^{34}$ & Nephrolithiasis & Bacterioscopic, bacteriological (animal model) \\
\hline Shen et $\mathrm{al}^{38}$ & Type III prostatitis & Bacterioscopic, bacteriological (animal model) \\
\hline Zhang et $\mathrm{al}^{39}$ & Interstitial cystitis/painful bladder syndrome & Serological, bacterioscopic, bacteriological \\
\hline Zhang et $\mathrm{al}^{40}$ & Testicular microlithiasis & Serological, bacterioscopic, bacteriological \\
\hline Tulunay Kaya et al $^{45}$ & Coronary artery calcification & Serological \\
\hline
\end{tabular}

Abbreviations: CNP, calcifying nanoparticle; HIV, human immunodeficiency virus. 
other studies that are mentioned below show that $\gamma$-irradiation of similar dose successfully copes with its role of preventing CNP formation in control media (hence, it sterilized the serum in all media). Also, Mathew et $\mathrm{a}^{28}$ found that CNPs are able to be cultivated even in media without serum.

The first and the most investigated is the connection of CNPs with risk of nephrolithiasis that was shown in 1998 by Kajander and Ciftçioglu, ${ }^{16}$ who revealed specific CNP antigens in all 30 examined kidney stones, and who also extracted and cultivated CNPs from these samples. These data were further proved in the investigation of Ciftçioglu et al, ${ }^{17}$ who indicated CNPs in $97.2 \%$ of examined kidney stones by several methods (eg, immunostaining, assessment of $\mathrm{Ca}$ and ${ }^{85} \mathrm{Sr}$ incorporation, and bacterioscopic and bacteriological methods). Moreover, based on the following statements, they proposed a theory that CNPs are an etiological agent of nephrolithiasis. ${ }^{17}$

- CNPs were identified, extracted and cultured from the vast majority of kidney stones.

- Almost all kidney stones contained apatite, which is a component of CNP mineral shell.

- CNPs are the only known agent producing apatite and depositing in the kidneys.

- CNPs that were extracted and cultured from kidney stones formed new ones during incubation.

- CNPs labeled by radioactive technetium $\left({ }^{99 \mathrm{~m}} \mathrm{Tc}\right)$ and intravenously injected into rabbits were renotropic and could be found in the urine.

- The results of similar studies conducted in distinct populations (Finnish and American) were close to each other.

This hypothesis was proved by Khullar et al, ${ }^{20}$ who identified CNPs in $62 \%$ of kidney stones in an Indian population using serological (Ouchterlony immunodiffusion test), bacterioscopic, and bacteriological methods. Kumar et $\mathrm{al}^{22}$ exploited serological, bacterioscopic, bacteriological, genomic, and proteomic assays and noted a probable role of CNPs in etiopathogenesis of Randall's plaques that are precursors of kidney stones of calcium oxalate. Subsequently their results were confirmed by Ciftçioglu et al, ${ }^{32}$ who detected CNPs in $\sim 70 \%-90 \%$ of kidney papillae samples afflicted by Randall's plaques serologically, bacterioscopically, and bacterologically (tests that were carried out had different sensitivity and specificity). Similar results were obtained during the analysis of serum from these patients. ${ }^{32}$ Furthermore, Chen et $\mathrm{al}^{33}$ indicated the presence of CNPs in the serum of $92 \%$ of patients with nephrolithiasis and the absence of them in the serum of control subjects, but it should be noted that the sample size was insufficient ( 24 cases and three controls). Hu et $\mathrm{al}^{34}$ demonstrated the ability of CNPs to cause nephrolithiasis in rats, and tetracycline possessed a specific antibacterial activity (inhibition of protein synthesis) as chelating activity prevented formation of kidney stones in this study. Earlier similar results were obtained in rats by Shiekh et al, ${ }^{26}$ but the number of rats in their investigation was too small (three cases and three controls). Moreover, the influence of tetracycline on kidney stone formation was not assessed in their study. ${ }^{26}$

In relation to other kidney diseases, Hjelle et a ${ }^{18}$ found CNPs in kidneys of patients with polycystic kidney disease by bacterioscopic and serological methods in 100\% of cases (eight cases out of eight, and 13 cases out of 13, respectively), and by bacteriological assays - in $84.6 \%$ of cases (eleven cases out of 13). The role of CNPs in etiology of this disorder remains unclear since there were no similar studies from that time, but it is known that nephrolithiasis is diagnosed in patients with polycystic kidney disease several times more often than in the general population. ${ }^{35}$

Also, the role of CNPs in etiopathogenesis of type III chronic prostatitis/chronic pelvic pain syndrome was investigated. Shoskes et $\mathrm{al}^{36}$ found that comET therapy (tetracycline + ethylenediaminetetraacetic acid [EDTA] + nutrients) for 3 months leads to at least a $25 \%$ improvement of conditions in $80 \%$ of patients with this disorder (according to the National Institute of Health Chronic Prostatitis Symptom Index) resistant to other therapeutic modalities, and in 53\% of cases this parameter was higher than $50 \%$. The size of stone decreased at least twofold in $50 \%$ of patients according to the results of a transrectal ultrasound test. ${ }^{36} \mathrm{CNP}$ antigens and anti-CNP antibodies were also detected in $60 \%$ of serum samples and in $40 \%$ of urine samples. ${ }^{36}$ In 2008 , Zhou et al ${ }^{37}$ carried out a placebo-controlled trial of therapy against CNPs on a larger sample of patients with type III chronic prostatitis resistant to other treatment. After the course of therapy, according to bacterioscopic and bacteriological methods, CNPs were found in expressed prostatic secretions of only $16.7 \%$ of patients (before treatment this rate was $62.5 \%$ ); whilst in the urine, CNPs were not detected at all (before treatment this parameter was $12.5 \%$ ). ${ }^{37}$ In a group of subjects who received placebo, no statistically significant decline of CNP detection rate was noted. ${ }^{37}$ Similar results were obtained in relation to the improvement of the condition of patients (according to the National Institute of Health Chronic Prostatitis Symptom Index). ${ }^{37}$ This led to the suggestion that CNPs play a role in the etiology of type III chronic prostatitis, and an effective method of treatment of this disease was proposed. ${ }^{37}$ Finally, in 2010, Shen et al ${ }^{38}$ 
demonstrated the influence of CNPs on the development of type III chronic prostatitis on the animal model, injecting CNPs into rats transurethrally. After 1-2 weeks from the beginning of the experiment, prostatic acute inflammatory changes were observed in rats exposed to CNPs; after 4 weeks, these inflammatory alterations became chronic. ${ }^{38}$ After the end of the 8 th week, $70 \%$ (7 out of 10 ) of the rats had microscopic calculi in the prostatic glandular cavity. ${ }^{38}$ Nothing of significance was detected in the control rats. ${ }^{38}$ The level of interleukin- $1 \beta$ and tumor necrosis factor- $\alpha$ in the prostate of model rats was higher than in control rats at all time points. ${ }^{38}$ The role of CNPs in the etiology of type III chronic prostatitis was thereby confirmed experimentally. ${ }^{38}$

In relation to other diseases of the genitourinary tract, Zhang et $\mathrm{al}^{39}$ proposed a role of CNPs in the etiology of interstitial cystitis/painful bladder syndrome and revealed them by serological, bacterioscopic, and bacteriological assays CNPs in $47.8 \%$ (11 out of 23 ) of bladder tissue samples of patients with this disorder, also demonstrating significant improvement of symptoms (up to complete convalescence) in $90.9 \%$ (10 out of 11) of these patients after tetracycline treatment (orally and intravesically). Moreover, after such therapy CNPs were detected in the bladder tissue in only $27.3 \%$ of cases ( 3 out of 11). ${ }^{39}$ The same authors hypothesized a feasible role of CNPs in the etiology of testicular microlithiasis and observed CNPs using serological, bacterioscopic, and bacteriological tests in $58.8 \%$ (10 out of 17 ) of semen samples of patients with this disease compared with 5.9\% (1 out of 17) of controls. ${ }^{40}$ Summing up, it is possible to conclude that CNPs play an important role in the development of the various diseases of the genitourinary tract, particularly affecting the risk and the course of nephrolithiasis and of type III chronic prostatitis/chronic pelvic pain syndrome.

A number of researchers have investigated the influence of CNPs on the etiopathogenesis of cardiovascular diseases. Maniscalco and Taylor ${ }^{41}$ serologically revealed that comET therapy (1500 mg of EDTA in a rectal suppository base, $500 \mathrm{mg}$ of tetracycline orally, and a mixture of various nutrients in powder orally; all indicated every evening) for 4 months may be effective against coronary artery disease, decreasing calcification of coronary arteries, which is presumably caused by the deposit of CNPs within them (it is known that CNPs are as sensitive to tetracycline as they are to EDTA). Miller et $\mathrm{al}^{21}$ found CNPs serologically, bacterioscopically, and bacteriologically in calcified aneurysms, cardiac valves, and plaques of carotid and femoral arteries, but did not detect them in noncalcified aneurysms, concluding that CNPs may cause calcification of cardiac valves and blood vessels. Similar results were obtained by Puskas et al, ${ }^{25}$ who serologically identified CNPs in 64.3\% (9 out of 14) of atherosclerotic plaques of carotid arteries and aorta, but did not observe them in five control samples of the same vessels. Furthermore, they successfully extracted and cultivated CNPs from 26 out of 42 calcified sclerotic samples of aortas and carotid arteries, which suggests their involvement in atherosclerosis etiology (particularly at the stage of blood vessel calcification). ${ }^{25}$ Bratoz-Perez et $\mathrm{al}^{42}$ detected CNPs in 48 out of 75 aortic valves with stenosis (64\%) by bacterioscopic and bacteriological methods, and did not reveal them in healthy valves (0 out of 8 ). In 2008, Schwartz et $\mathrm{al}^{31}$ demonstrated CNP toxicity for arteries in the animal model (rabbits). Damaging carotid arteries on the one side and using contralateral carotid arteries as controls, they tested them for susceptibility to exposure to intravenously injected saline, mineralized CNPs, or demineralized CNPs. ${ }^{31}$ Damaged arteries exposed to mineralized CNPs were occluded, sometimes with canalization, and mineralized CNPs from kidney stones formed calcifications inside occluded vessels. ${ }^{31}$ Demineralized CNPs from kidney stones induced minimal eccentric intima hyperplasia in damaged arteries (as saline), whilst demineralized CNPs from calcified arteries caused moderate hyperplasia or occlusion with canalization and calcifications. ${ }^{31}$ CNPs may therefore lead to occlusion and calcification of damaged arteries, ${ }^{31}$ and it is important that they can induce pathological processes in blood vessels even without a mineral shell (see above). Arteries with healthy endothelium were resistant to exposure to CNPs. ${ }^{31}$ Candemir et al, ${ }^{43}$ in an epidemiological investigation by enzyme-linked immunosorbent assay (ELISA) found a connection between the level of anti-CNP antibodies and the risk of mitral annular calcification and with the thickness of calcification, suggesting the following mechanisms of this association:

- Colonization of mitral valve by CNPs induces an immune response, promoting inflammation development and further calcification, closing the "vicious circle." CNPs may also form calcifications in adjacent tissues on their own after the colonization.

- CNPs may alter the composition and quantity of microflora in the place of colonization that may lead to bacterial infection and to formation of biofilms. Furthermore, calcification itself promotes colonization of afflicted tissue by other possibly pathogenic bacteria.

$\mathrm{Hu}$ et $\mathrm{al}^{44}$ serologically, bacterioscopically and bacteriologically found a connection between CNPs and the calcification of cardiac valves during rheumatic heart disease. In their study, CNPs were identified in $89.6 \%$ of calcified 
samples (26 out of 29) and in none of control samples. ${ }^{44}$ Finally, Tulunay Kaya et $\mathrm{a}^{45}$ used ELISA to show the association between the level of anti-CNP antibodies and the risk and severity of calcification of coronary arteries. Results of all studies devoted to the relation of CNPs with pathological calcification of cardiac valves and blood vessels suggest that this connection probably exists.

In a number of studies, the connection of CNPs with other diseases associated with pathological calcification has also been investigated. Sedivy and Battistutti ${ }^{46}$ found CNP antigens in 100\% (7 out of 7) of ovarian malignant tumors in which psammoma bodies (which are microcalcifications) were detected, whilst in samples without such microcalcifications these antigens were not observed. ${ }^{46}$ Their results were completely proved by Hudelist et al, ${ }^{19}$ who identified CNP antigens in eight out of eight ovarian neoplasms containing psammoma bodies, and did not detect them in ten out of ten tumors without these microcalcifications. Interestingly, in this investigation, the extraction of mRNA of CNPs from all tumor samples with psammoma bodies was successful, whilst all attempts to do this in the cases with tumors without psammoma bodies failed. ${ }^{19}$ Wen et $\mathrm{al}^{47}$ have shown that CNP antigens are significantly more often detected in the serum of patients with cholecystolithiasis (31.6\%) compared with control group (8\%). Moreover, it was observed that the gallbladder mucosa is infected by CNPs during cholecystolithiasis in $35 \%$ of cases. ${ }^{47}$ Of interest, $42.5 \%$ of patients had CNP antigens in their bile but not their gallbladder mucosa, which suggests that gallbladder mucosa has the ability to prevent CNP infiltration, but when CNPs invade the mucosa and submucosa, they may form calcifications and cause gallbladder fibrosis. ${ }^{47}$ Wang et $\mathrm{al}^{23}$ observed that CNPs, extracted from the bile of patients with cholecystolithiasis, may cause formation of black pigment gallstones in rabbits after the intravesical injection in $80 \%$ of cases (eight out of ten), whilst hydroxyapatite crystals and culture media for CNPs led to the occurrence of such gallstones only in $20 \%$ of cases (two out of ten). These authors therefore concluded that CNPs can be a cause of cholecystolithiasis (particularly in the case with black pigment gallstones), and inorganic hydroxyapatite crystals are not equivalent to CNPs in the ability to induce this pathological condition, ${ }^{23}$ which is consistent with the results of Schwartz et al, ${ }^{31}$ who have also shown in an animal model that hydroxyapatite cannot be fully responsible for pathogenic activity of CNPs.

Pretorius et $\mathrm{al}^{48}$ investigated the prevalence of CNP antigens and anti-CNP antibodies in human immunodeficiency virus (HIV)-infected women and healthy women in South
Africa. According to the results of their study, anti-CNP antibodies and CNP antigens were found in 85\% and 7.5\% of HIV-infected women, respectively, whilst in the control group these rates were 5\% for both CNP antigens and antiCNP antibodies. ${ }^{48}$ Interestingly, amongst the offspring of HIV-infected mothers, 70\% had CNP antigens according to the results of ELISA, and antigen levels in their blood was higher compared with the mothers. ${ }^{48}$ Two HIV-positive babies were characterized by the highest level of these antigens in the blood, and blood of their mothers also contained CNP antigens. ${ }^{48}$ Based on the results, the authors proposed an opportunistic nature of CNP invasion, ${ }^{48}$ and also proposed the possibility of transplacental or perinatal transmission of CNPs from mothers to offspring. Finally, the feasible role of CNPs in the etiology of pathological placental calcification was shown bacterioscopically. ${ }^{49}$

\section{Conclusion}

This epistemological analysis shifts the balance between the two hypotheses (the physicochemical and the biological nature of CNPs) in favor of the biological one, making the term "nanobacteria" relevant again, but at the same time it is obvious that discussions about the nature of CNPs will continue until their genome can be fairly accurately sequenced. However, it is clear that CNPs play an important role in the etiopathogenesis of many diseases, and this connection is independent of their nature, although results of conducted epidemiological studies and experimental investigations on animal models prove their biological origin. Hence, the emergence of CNPs in the organism is a pathological, not a physiological, process. Thereafter, the actual problem of studying CNPs is the development of effective methods of etiotropic treatment of diseases related to them, and also the development of specific preventive measures and diagnostic assays. Existing serological tests are suspected in the insufficient specificity because of cross-reactivity of MoAbs to CNP antigens with proteins of biological liquids, bacterioscopic methods are too difficult, expensive and labor-intensive, and bacteriological assays require too long a time for their conduction. The relevance of genomic method (polymerase chain reaction) is doubtful because of problems with specificity of existing primers to putative nucleotide sequences of CNPs, and the development of proteomic assays is only at the early stages. The prospective directions are the development of more specific CNP antigens and anti-CNP MoAbs, and also the development of new media for accelerated CNP cultivation (it can also facilitate the usage of bacterioscopic method as microscopic colonies of CNPs can be analyzed by light 
microscopy with von Kossa staining, which is more available and cheaper than electron microscopy). Correct sequencing of the CNP genome will definitely lead to the appearance of specific primers and to the development of genomic CNPrelated assays. Also, further investigations devoted to the exploration of sensitivity and resistance of CNPs to various antimicrobial chemotherapeutics, used in medical practice for therapy and disinfection, are needed. The possibilities for the prevention of CNP-associated diseases can be optimally analyzed from ecological and hygienic as well as from chemopreventive points of view. Such complex measures should reduce economic losses, incidence, disability, and mortality from CNP-associated diseases, and also increase quality of life of these patients. It is obvious that to reach this aim, basic, translational, and clinical studies are necessary.

Further investigations in the CNP research field may be classified as follows:

- Fundamental studies that are focused on the extraction of CNP nucleic acids with subsequent sequencing of their genome, which will prove they are the smallest self-replicating life form on Earth, and to the studying of various properties of CNPs, including pathogenic ones. Many already performed basic investigations (for instance, those where the presence of DNA in CNPs was proved by positive DNA-specific staining, but DNA was not extracted $)^{17,18,20,21,23,24}$ are close to this group, and they can be represented as "first generation" studies. Investigations by Hudelist et $\mathrm{al}^{19}$ and Kumar et $\mathrm{al}^{22}$ may be represented as prototypes for further investigation (in another words, they can be represented as "second generation" studies), since CNP nucleic acids were successfully extracted, although accurate sequencing was not conducted. Consequently, investigations in which fairly accurate sequencing of the CNP genome will be carried out will represent "third generation" studies.

- Basic studies that are focused on the investigation of features of immune response against CNPs. To date, no comprehensive investigations of this group have been performed, although in some studies the prevalence of CNP antigens and anti-CNP antibodies among various populations ${ }^{27}$ and under the various pathological conditions has been analyzed..$^{36,43,45,48}$ Further investigations of this group should denote the role of certain components of cellular and humoral arms of the immune response (for instance, the significance of various lymphocyte subsets and cytokines) in CNP-associated diseases. Similarly, the features of innate and adaptive immune response against CNPs should be defined, the regulation of CNP-induced immune response should be uncovered, the peculiarities of immunological memory against CNPs should be analyzed, and the possibilities of immunotherapy of CNP-associated diseases may be investigated.

- Fundamental studies that are focused on the development of new methods of CNP identification and diagnostics of CNP-associated diseases (for instance, they should be directed to the extraction of new specific CNP antigens or new specific anti-CNP MoAbs, to the invention of new culture media, and also to the development of new staining methods). They could lead to a similar breakthrough in the field as was made after the studies of Kajander and Ciftçioglu, ${ }^{16}$ Kumar et al, ${ }^{22}$ and Shiekh et al, ${ }^{26}$ in which many new methods of working with CNPs were described.

- Experimental studies on animal models and epidemiological studies that are focused on the uncovering of new connections between CNPs and the etiopathogenesis of various diseases, and also to the search, trial, and approbation of new ways of treating CNP-associated diseases. To date, certain studies of this type have been successfully performed (as investigations on animal models ${ }^{23,26,31,34,38}$ and as epidemiological studies $\left.{ }^{16,22,25,32,33,36,37,39-49}\right)$. Two papers indicate comET-therapy as a possible effective method of treatment of CNP-associated diseases. ${ }^{36,41}$ Further studies certainly will lead to the discovery of new associations between CNPs and pathological conditions, and to the development of new methods of treatment of CNP-associated diseases. It is important to underline the necessity of increasing the sample size in future epidemiological investigations, since in the majority of studies to date, the sample sizes have been insufficient to accurately assess the significance of the apparent connection. The combination of distinct methods (serological, bacterioscopic, and bacteriological) of CNP identification in biological samples is needed as well. This is also the case for the experiments on animal models, in which it is necessary to denote several groups to the study of features of mineralized and demineralized CNPs (as was done in the study of Schwartz et $\mathrm{al}^{31}$ ), and for the comparison of effects caused by CNPs with ones caused by hydroxyapatite crystals (as was done in the investigation of Wang et $\mathrm{al}^{23}$ ).

- Ecological, hygienic, and pharmacological studies that are focused on the prevention of CNP-associated diseases. To date, no such investigations have been conducted; however, studies by Shoskes et $\mathrm{al}^{36}$ and Maniscalco and Taylor ${ }^{41}$ point to the possible role of comET-therapy for the purpose of chemoprevention. Obviously, 
development, approbation, and implementation of the preventive measures against CNP-associated diseases should be the aims of future research.

Undoubtedly, basic, translational, and clinical investigations that will be carried out in the future will clarify the role of CNPs in biology and medicine and will enable significant progress in the theoretical and practical fields of these sciences.

\section{Disclosure}

The authors report no conflicts of interest in this work.

\section{References}

1. Kajander EO, Kuronen I, Akerman K, Pelttari A, Ciftcioglu N. Nanobacteria from blood, the smallest culturable autonomously replicating agent on earh. Proc Soc Photo Opt Instrum Eng. 1997;3111: 420-428

2. Cisar JO, Xu DQ, Thompson J, Swaim W, Hu L, Kopecko DJ. An alternative interpretation of nanobacteria-induced biomineralization. Proc Natl Acad Sci U S A. 2000;97(21):11511-11515.

3. Drancourt M, Jacomo V, Lépidi H, et al. Attempted isolation of Nanobacterium sp. microorganisms from upper urinary tract stones. J Clin Microbiol. 2003;41(1):368-372.

4. Urbano P, Urbano F. Nanobacteria: facts or fancies? PLoS Pathog. 2007;3(5):e55.

5. Raoult D, Drancourt M, Azza S, et al. Nanobacteria are mineralo fetuin complexes. PLoS Pathog. 2008;4(2):e41.

6. Martel J, Young JD. Purported nanobacteria in human blood as calcium carbonate nanoparticles. Proc Natl Acad Sci U S A. 2008;105(14): $5549-5554$.

7. Martel J, Wu CY, Young JD. Critical evaluation of gamma-irradiated serum used as feeder in the culture and demonstration of putative nanobacteria and calcifying nanoparticles. PLoS One. 2010;5(4): e10343.

8. Wu CY, Martel J, Young D, Young JD. Fetuin-A/albumin-mineral complexes resembling serum calcium granules and putative nanobacteria: demonstration of a dual inhibition-seeding concept. PLoS One. 2009;4(11):e8058.

9. Young JD, Martel J, Young D, et al. Characterization of granulations of calcium and apatite in serum as pleomorphic mineralo-protein complexes and as precursors of putative nanobacteria. PLoS One. 2009;4(5):e5421.

10. Young JD, Martel J, Young L, Wu CY, Young A, Young D. Putative nanobacteria represent physiological remnants and culture by-products of normal calcium homeostasis. PLoS One. 2009;4(2):e4417.

11. Kumon H, Matsumoto A, Uehara S, et al. Detection and isolation of nanobacteria-like particles from urinary stones: long-withheld data. Int J Urol. 2011;18(6):458-465.

12. Schlieper G, Krüger T, Heiss A, Jahnen-Dechent W. A red herring in vascular calcification: "nanobacteria" are protein-mineral complexes involved in biomineralization. Nephrol Dial Transplant. 2011;26(11):3436-3439.

13. Maniloff J. Nannobacteria: size limits and evidence. Science. 1997;276(5320):1776.

14. Glass JI, Assad-Garcia N, Alperovich N, et al. Essential genes of a minimal bacterium. Proc Natl Acad Sci U SA. 2006;103(2):425-430.

15. Volke F. Nannobacteria: size limits and evidence. 1997. Available at: http://naturalscience.com/ns/letters/ns_let02.html. Accessed on December 20, 2012.

16. Kajander EO, Ciftçioglu N. Nanobacteria: an alternative mechanism for pathogenic intra- and extracellular calcification and stone formation. Proc Natl Acad Sci U SA. 1998;95(14):8274-8279.
17. Ciftçioglu N, Björklund M, Kuorikoski K, Bergström K, Kajander EO. Nanobacteria: an infectious cause for kidney stone formation. Kidney Int. 1999;56(5):1893-1898.

18. Hjelle JT, Miller-Hjelle MA, Poxton IR, et al. Endotoxin and nanobacteria in polycystic kidney disease. Kidney Int. 2000;57(6):2360-2374.

19. Hudelist G, Singer CF, Kubista E, et al. Presence of nanobacteria in psammoma bodies of ovarian cancer: evidence for pathogenetic role in intratumoral biomineralization. Histopathology. 2004;45(6): 633-637.

20. Khullar M, Sharma SK, Singh SK, et al. Morphological and immunological characteristics of nanobacteria from human renal stones of a north Indian population. Urol Res. 2004;32(3):190-195.

21. MillerVM, Rodgers G, Charlesworth JA, et al. Evidence of nanobacteriallike structures in calcified human arteries and cardiac valves. $\mathrm{Am} \mathrm{J}$ Physiol Heart Circ Physiol. 2004;287(3):H1115-H1124.

22. KumarV, Farell G, Yu S, et al. Cell biology of pathologic renal calcification: contribution of crystal transcytosis, cell-mediated calcification, and nanoparticles. J Investig Med. 2006;54(7):412-424.

23. Wang L, Shen W, Wen J, An X, Cao L, Wang B. An animal model of black pigment gallstones caused by nanobacteria. Dig Dis Sci. 2006;51(6):1126-1132.

24. Zhou HD, Li GY, Yang YX, et al. Intracellular co-localization of SPLUNC1 protein with nanobacteria in nasopharyngeal carcinoma epithelia HNE1 cells depended on the bactericidal permeability increasing protein domain. Mol Immunol. 2006;43(11): 1864-1871.

25. Puskás LG, Tiszlavicz L, Rázga Z, Torday LL, Krenács T, Papp JG. Detection of nanobacteria-like particles in human atherosclerotic plaques. Acta Biol Hung. 2005;56(3-4):233-245.

26. Shiekh FA, Charlesworth JE, Kim SH, et al. Proteomic evaluation of biological nanoparticles isolated from human kidney stones and calcified arteries. Acta Biomater. 2010;6(10):4065-4072.

27. Kajander EO, Ciftcioglu N, Aho K, Garcia-Cuerpo E. Characteristics of nanobacteria and their possible role in stone formation. Urol Res. 2003;31(2):47-54.

28. Mathew G, Mckay DS, Ciftçioglu N. Do blood-borne calcifying nanoparticles self-propagate? Int J Nanomedicine. 2008;3(2):265-275.

29. Sommer AP, Hassinen HI, Kajander EO. Light-induced replication of nanobacteria: a preliminary report. J Clin Laser Med Surg. 2002;20(5): 241-244.

30. Cíftçíoglu N, Miller-Hjelle MA, Hjelle JT, Kajander EO. Inhibition of nanobacteria by antimicrobial drugs as measured by a modified microdilution method. Antimicrob Agents Chemother. 2002;46(7):2077-2086.

31. Schwartz MA, Lieske JC, Kumar V, Farell-Baril G, Miller VM. Human-derived nanoparticles and vascular response to injury in rabbit carotid arteries: proof of principle. Int J Nanomedicine. 2008;3(2): 243-248.

32. Ciftçioglu N, Vejdani K, Lee O, et al. Association between Randall's plaque and calcifying nanoparticles. Int J Nanomedicine. 2008;3(1):105-115.

33. Chen L, Huang XB, Xu QQ, Li JX, Jia XJ, Wang XF. Cultivation and morphology of nanobacteria in sera of patients with kidney calculi. Beijing Da Xue Хие Bao. 2010;42(4):443-446.

34. Hu WG, Wang XF, Xu T, et al. Establishment nephrolithiasis rat model induced by nanobacteria and analysis of stone formation. Beijing $D a$ Хие Хие Вао. 2010;42(4):433-435.

35. Torres VE, Wilson DM, Hattery RR, Segura JW. Renal stone disease in autosomal dominant polycystic kidney disease. Am J Kidney Dis. 1993;22(4):513-519.

36. Shoskes DA, Thomas KD, Gomez E. Anti-nanobacterial therapy for men with chronic prostatitis/chronic pelvic pain syndrome and prostatic stones: preliminary experience. J Urol. 2005;173(2):474-477.

37. Zhou Z, Hong L, Shen X, et al. Detection of nanobacteria infection in type III prostatitis. Urology. 2008;71(6):1091-1095.

38. Shen X, Ming A, Li X, Zhou Z, Song B. Nanobacteria: a possible etiology for type III prostatitis. J Urol. 2010;184(1):364-369. 
39. Zhang QH, Shen XC, Zhou ZS, Chen ZW, Lu GS, Song B. Decreased nanobacteria levels and symptoms of nanobacteria-associated interstitial cystitis/painful bladder syndrome after tetracycline treatment. Int Urogynecol J. 2010;21(1):103-109.

40. Zhang QH, Lu GS, Shen XC, et al. Nanobacteria may be linked to testicular microlithiasis in infertility. J Androl. 2010;31(2):121-125.

41. Maniscalco BS, Taylor KA. Calcification in coronary artery disease can be reversed by EDTA-tetracycline long-term chemotherapy. Pathophysiology. 2004;11(2):95-101.

42. Bratos-Pérez MA, Sánchez PL, García de Cruz S; for Grupo AORTICA (Grupo de Estudio de la Estenosis Aórtica). Association between selfreplicating calcifying nanoparticles and aortic stenosis: a possible link to valve calcification. Eur Heart J. 2008;29(3):371-376.

43. Candemir B, Ertas FS, Kaya CT, et al. Association between antibodies against calcifying nanoparticles and mitral annular calcification. J Heart Valve Dis. 2010;19(6):745-752.
44. Hu YR, Zhao Y, Sun YW, et al. Detection of nanobacteria-like material from calcified cardiac valves with rheumatic heart disease. Cardiovasc Pathol. 2010;19(5):286-292.

45. Tulunay Kaya C, Sinan Ertas F, Hasan T, et al. Anticalcifying nanoparticle antibody titer is an independent risk factor for coronary artery calcification. Coron Artery Dis. 2011;22(6):394-400.

46. Sedivy R, Battistutti WB. Nanobacteria promote crystallization of psammoma bodies in ovarian cancer. APMIS. 2003;111(10):951-954.

47. Wen Y, Li YG, Yang ZL, et al. Detection of nanobacteria in serum, bile and gallbladder mucosa of patients with cholecystolithiasis. Chin Med J (Engl). 2005;118(5):421-424.

48. Pretorius AM, Sommer AP, Aho KM, Kajander EO. HIV and nanobacteria. HIV Med. 2004;5(6):391-393.

49. Agababov RM, Abashina TN, Suzina NE, Vainshtein MB, Schwartsburd PM. Link between the early calcium deposition in placenta and nanobacterial-like infection. J Biosci. 2007;32(6):1163-1168.
International Journal of Nanomedicine

\section{Publish your work in this journal}

The International Journal of Nanomedicine is an international, peerreviewed journal focusing on the application of nanotechnology in diagnostics, therapeutics, and drug delivery systems throughout the biomedical field. This journal is indexed on PubMed Central, MedLine, CAS, SciSearch $\AA$, Current Contents ${ }^{\circledR} /$ Clinical Medicine,

\section{Dovepress}

Journal Citation Reports/Science Edition, EMBase, Scopus and the Elsevier Bibliographic databases. The manuscript management system is completely online and includes a very quick and fair peer-review system, which is all easy to use. Visit http://www.dovepress.com/ testimonials.php to read real quotes from published authors. 